\title{
COMPARISON OF NONLINEAR STATIC AND DYNAMIC ANALYSES ON A R/C BUILDING
}

\author{
Muhammed Tekin ${ }^{1}$, Ali Gürbüz ${ }^{2, *}$ and Ali Demir ${ }^{1}$ \\ ${ }^{1}$ Department of Civil Engineering, Celal Bayar University, 45140 \\ Muradiye, Manisa, Turkey \\ ${ }^{2}$ Department of Civil Engineering, Recep Tayyip Erdogan University, 53100 Fener, \\ Rize, Turkey \\ mdtekin@cbu.edu.tr, ali.gurbuz@erdogan.edu.tr, ali.demir@cbu.edu.tr
}

\begin{abstract}
In recent years, nonlinear calculation methods can be easily carried out by means of developing computer technologies. In this way, comparisons of the nonlinear methods have started to increase rapidly and more studies are carried out on regular and irregular buildings. However, it is most important to compare consistency of the methods on buildings. In this study, most common nonlinear static (pushover) and nonlinear dynamic analysis (time history analysis) methods were compared on an asymmetric planned reinforced concrete $(\mathrm{R} / \mathrm{C})$ building. Building having horizontal and vertical irregularities was 5-story. Analyses were carried out by using SAP2000 program. The results are discussed in terms of base shear, lateral displacements and top displacement ratios.
\end{abstract}

Key Words- R/C Buildings, Irregular Building, Nonlinear Time History Analysis, Nonlinear Pushover Analysis

\section{INTRODUCTION}

It is possible to use linear or nonlinear methods in seismic analyses of structures. Linear analysis uses the methods of the elastic solution. Inelastic behavior includes to solution by specific coefficients. Results obtained from elastic analyses are lower realistic than inelastic analyses. It is need to include inelastic behavior of structural elements for more realistic results. Nonlinear time history $(\mathrm{TH})$ analysis is the represents the most actual behavior of the structure. However, developing computer technologies provide easy to carry out it. TH analyses need to long time period bacause of multi-parameter solution way. Seismic loads are applied to the building directly in TH method. Earthquake data should be selected carefully. There have been some studies completed by using time history method [1, 2, 3, 4]. Past studies shows that nonlinear pushover (NSP) analysis is suitable alternative to $\mathrm{TH}$ by correct selection of parameters and assumptions. Studies of Saiidi and Sozen [5] provided static pushover analyses occurrence and improvement. In addition, ATC 40 [6], FEMA 273 [7], FEMA 356 [8] and FEMA 440 [9] procedures were introduced. In parallel with these procedures, Turkish Seismic Code (TSC-2007) came into effect in 2007 [10]. Chapter 7 of TSC-2007 entitled "Assessment and Strengthening of Existing Buildings" sets standards for assessment and rehabilitation of existing buildings. Bhatt and Bento [11] presented on assessment of two existing five and eight story plan asymmetric buildings in Turkey. These buildings were analyzed 
according to Adaptive Capacity Spectrum Method, Capacity Spectrum Method, N2 Method and Modal Pushover Analysis. Results obtained from analyses were compared. In this study, 5-story RC building having vertical and plan irregulars were selected to compare the results of NSP and TH analyses. Results were discussed in terms of base reactions, lateral displacements, top displacement ratios, interstory drifts and intensity levels.

\section{NUMERICAL METHOD}

Linear calculation methods are based on first order linear elastic theory. As an example, linear methods assume that the building materials behave linear elastic. Nonlinear behavior of structural material includes to the solition using some specific coefficients. However this linear assumption may give reliable results on the linear part of momentcurvation graphic, it ignores the actual energy absorption capacity of the structure. In order to determine the failure mechanism in the right way, it needs to consider nonlinear behavior of materials. In this study, modified Kent-Park Model was used for nonlinear concrete behavior.

Capacity curves of the structure were obtained by nonlinear static pushover (NSP) analysis. NSP analysis can be applied with two different ways. One of them is force controlled and the other one is displacement controlled analysis method. In this study, both of two techniques were used. First, forced controlled NSP was applied until reaching target displacement level, and then incremental displacement controlled NSP was applied. FEMA 356 values have been used for cracking stiffness of the structural system elements. Plastic deformations where in plastic sections and building material behaves linear elastic in other areas have been adopted. In the other hand, plastic deformations form by bending moment in beams, bending moment and axial forces in columns have been adopted. ATC 40 values were used for plastic rotations and plastic hinge values.

Two different earthquake acceleration records (1999 Duzce and 1992 Erzincan) were used for dynamic analyses. Nonlinear analyses were performed by Sap2000 computer program.

\section{CASE STUDY}

$\mathrm{R} / \mathrm{C}$ building with vertical and plan irregular was selected for this work. The building which is a real existing in Turkey was designed according to the 1975 Turkish Seismic Code. All of the floors have the same height of $2.80 \mathrm{~m}$ but it of base floor is $4.00 \mathrm{~m}$. The building from first floor to fourth floors building has 30x60 cm beams and 30x50 $\mathrm{cm}$ at fifth floor. 2 columns has $80 \times 30 \mathrm{~cm}$ section area, all of other column sections are $30 \times 60 \mathrm{~cm}$ and $60 \times 30 \mathrm{~cm}$. The stirrups have a diameter of $8 \mathrm{~mm}$ with $20 \mathrm{~cm}$ spacing constant along the height. There is no confinement for stirrups. The mass of fifth story is calculated to be 220 ton, all of other stories is calculated 278 ton. The building plan is shown in Figure 1. 


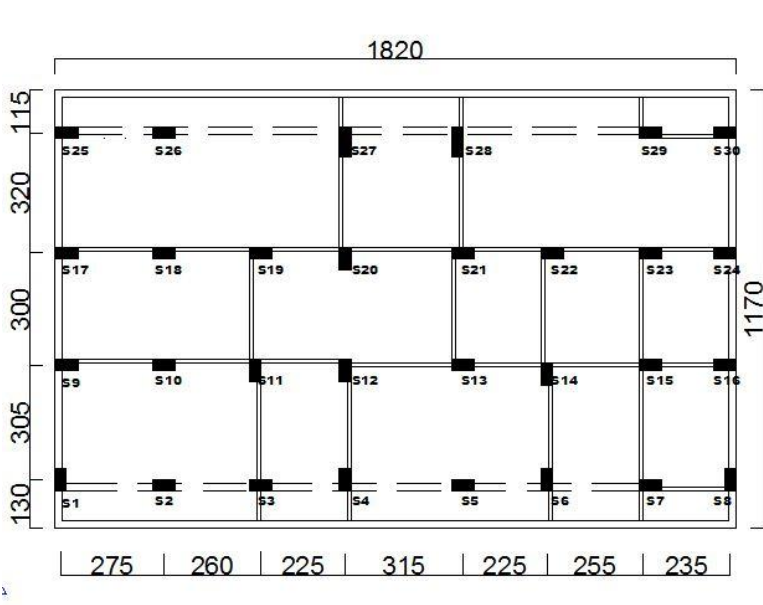

(a)

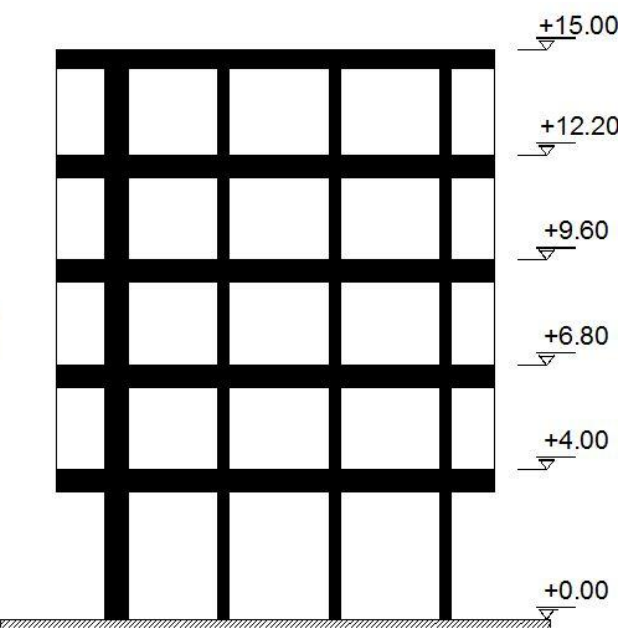

(b)

Figure 1. (a) Plan view (cm); (b) lateral view (m)

\section{MODELLING ISSUES}

This study performed by using Sap2000 nonlinear analysis program. Columns defined as reinforced concrete elements which work for axial load, M2 and M3 moment. As for beams, they defined reinforced concrete element which working M3 moment. The rigid diaphragm effect was modelled using "joint constrains" properties. C16 Concrete and S220 still classes used according to Turkish Standard (TS500). Adopted Kent Park model was used for nonlinear behavior of concrete. Damping of the building was considered as $\% 5$.

Two different (1999 Duzce and 1992 Erzincan) earthquake accelerations were used for nonlinear dynamic analysis. Earthquake records used in the analysis are shown in Table 1. These records are downloaded from (http://www.peer.berkeley.edu/). Five different $(0.1 \mathrm{~g}, 0.2 \mathrm{~g}, 0.4 \mathrm{~g}, 0.6 \mathrm{~g}$ and $0.8 \mathrm{~g})$ ground motion levels of intensity were performed for $\mathrm{X}$ and $\mathrm{Y}$ directon in each analysis. 20 nonlinear time history analyses were totally applied.

Table 1. Ground motion records from destructive earthquakes in Turkey

\begin{tabular}{|c|c|c|c|c|}
\hline $\begin{array}{c}\text { Earthquake } \\
\text { Name }\end{array}$ & Year & ClstD $(\mathbf{k m})$ & $\begin{array}{c}\text { Earthquake } \\
\text { Magnitude }\end{array}$ & PGA (g) \\
\hline Duzce & 1999 & 8.2 & 7.2 & 0.535 \\
\hline Erzincan & 1992 & 2.0 & 6.8 & 0.515 \\
\hline
\end{tabular}

ClstD: Closest distance to fault rupture

\section{ANALYSIS RESULTS}

The results of the building are presented in terms of base reaction, lateral displacement, top displacement ratio and interstory drifts for different level of seismic intensities.

The capacity curve which obtained as a result of the NSP analysis for X and Y directions are shown in Figure 2. It is compared with the results which obtained TH analysis for different ground motion levels of intensity. 


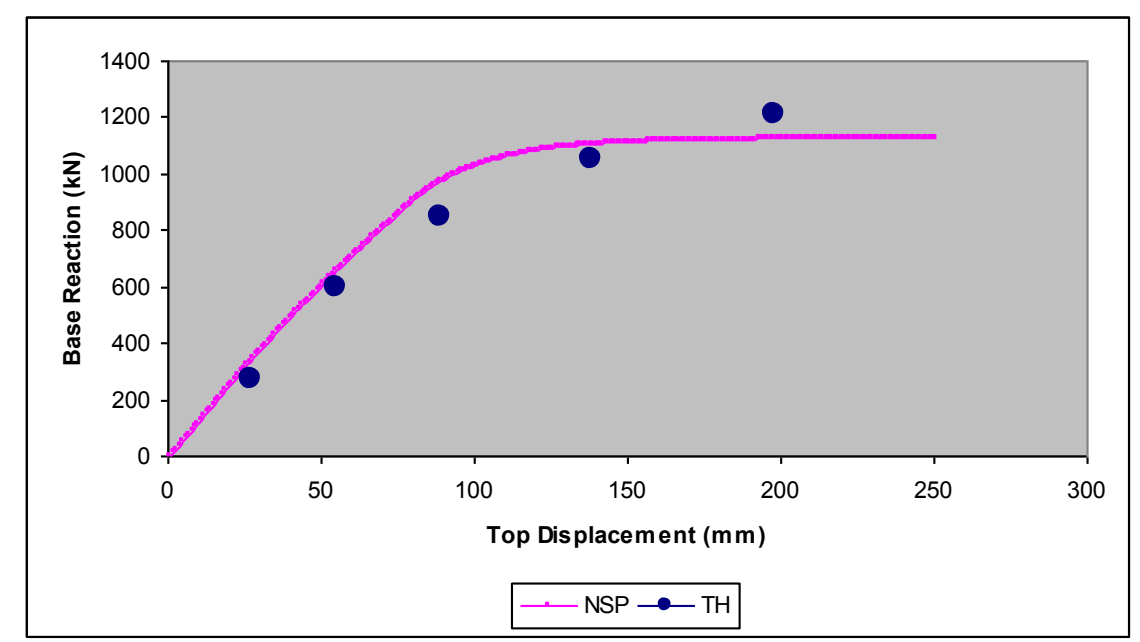

a) X Direction

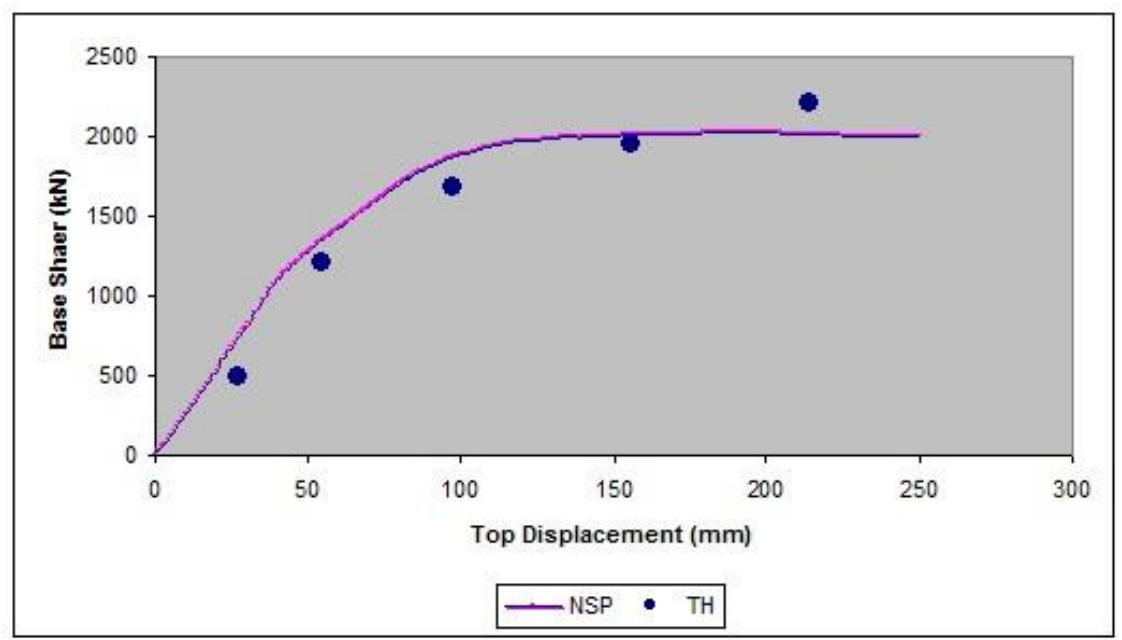

b) Y Direction

Figure 2. The Building Capacity Curves

$0.1 \mathrm{~g}$ and $0.2 \mathrm{~g}$ TH results are in agreement with NSP results in elastic part of graphic. As for inelastic part, difference of NSP results with TH results grew. When X and Y directions capacity curves were compared, It was observed that the structure is stronger in $\mathrm{Y}$ direction as expected. Bhatt and Bento [11] has suggested to use top displacement ratios for comparing with results of NSP and TH methods.

According to this:

Top displacement ratios $=\frac{\text { Nonlineer Pushover Top Displacement }}{\text { Time History Median Top Displacement }}$

This ratio gives the best result in center of masses. If the ratio move away from 1 , it means that the results are inconsistent. The ratio how approach to 1 , it is evaluated that the results are nearer to each other. Top displacement ratios for different intensity levels of ground motions are shown in Figure 3. 


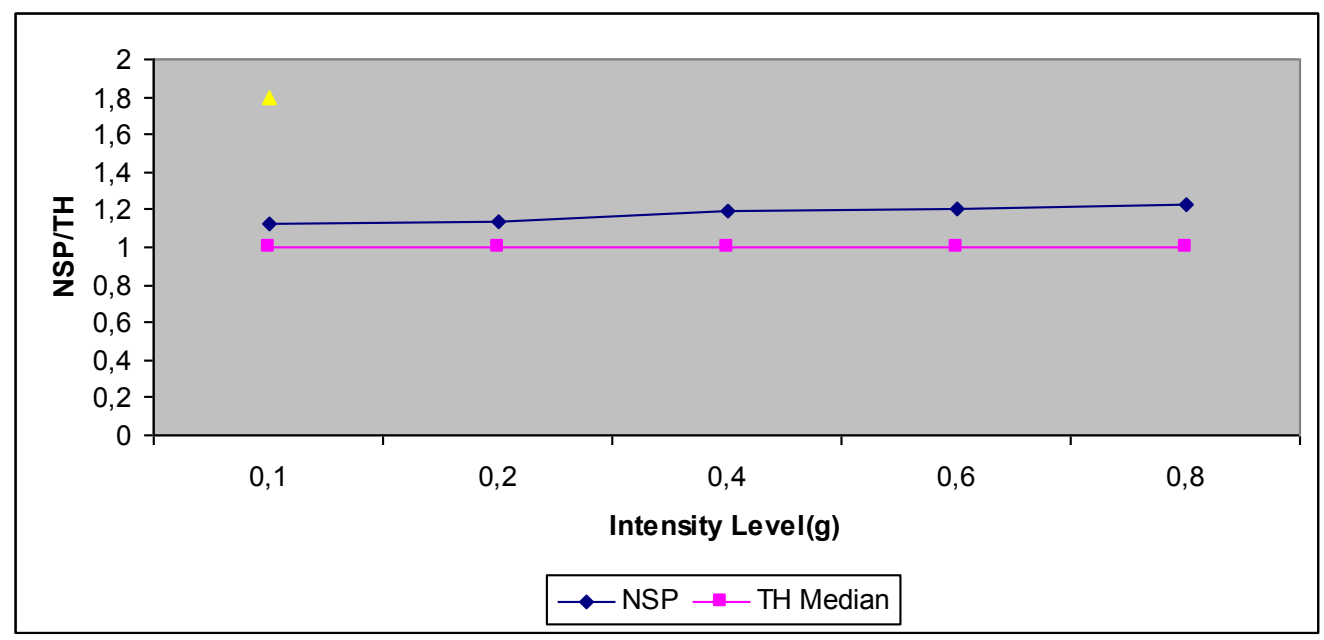

a) X Direction

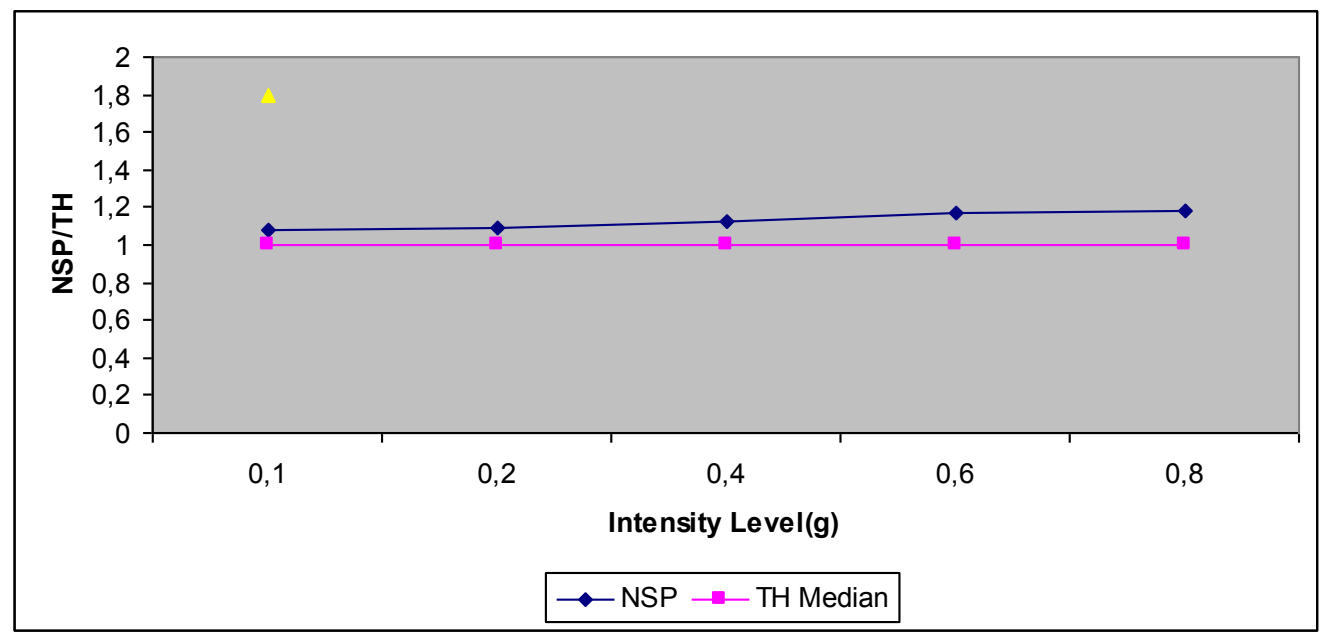

b) Y Direction

Figure 3. Top displacement ratios in the center of mass

Top displacement ratio was over 1 in each analysis. The ratio was closer to 1 in $0.1 \mathrm{~g}$ and $0.2 \mathrm{~g}$ intensity levels but values moved away to 1 for higher levels of intensity. NSP values departs from TH with increasing intensity levels. 


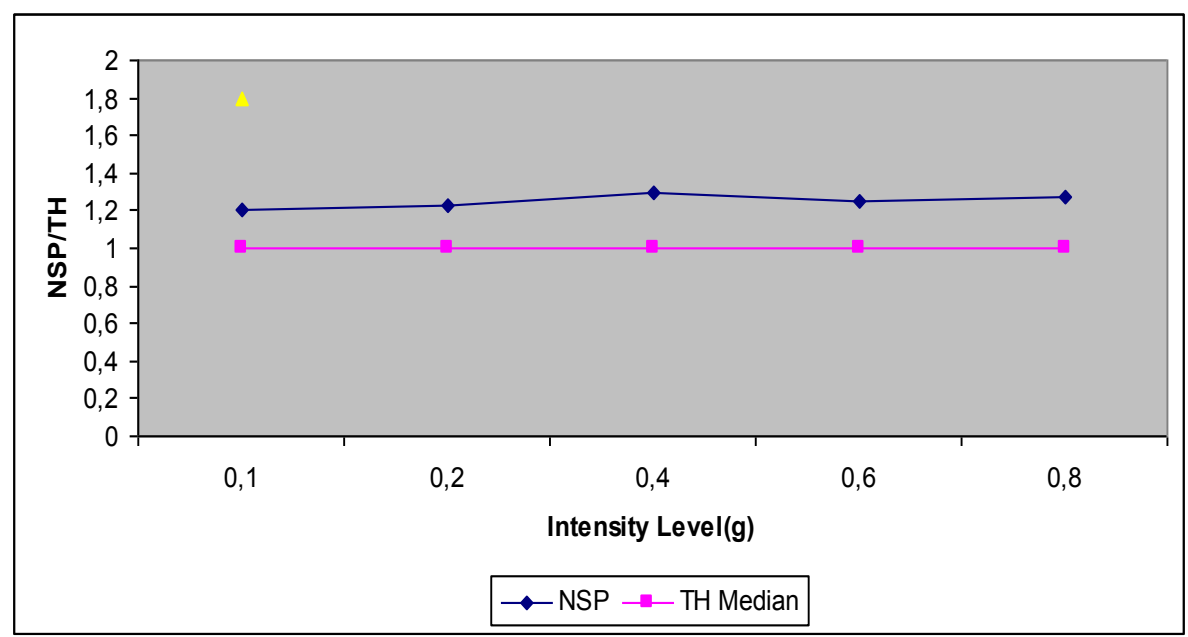

a) X Direction

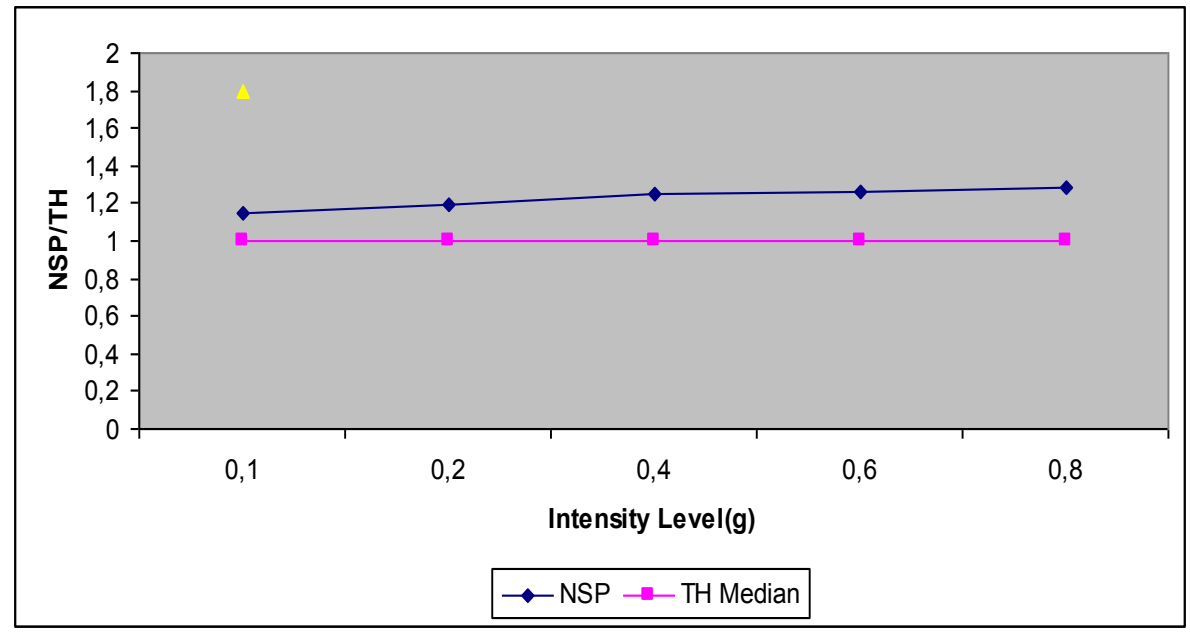

b) Y Direction

Figure 4. Top displacement ratios for Column S1

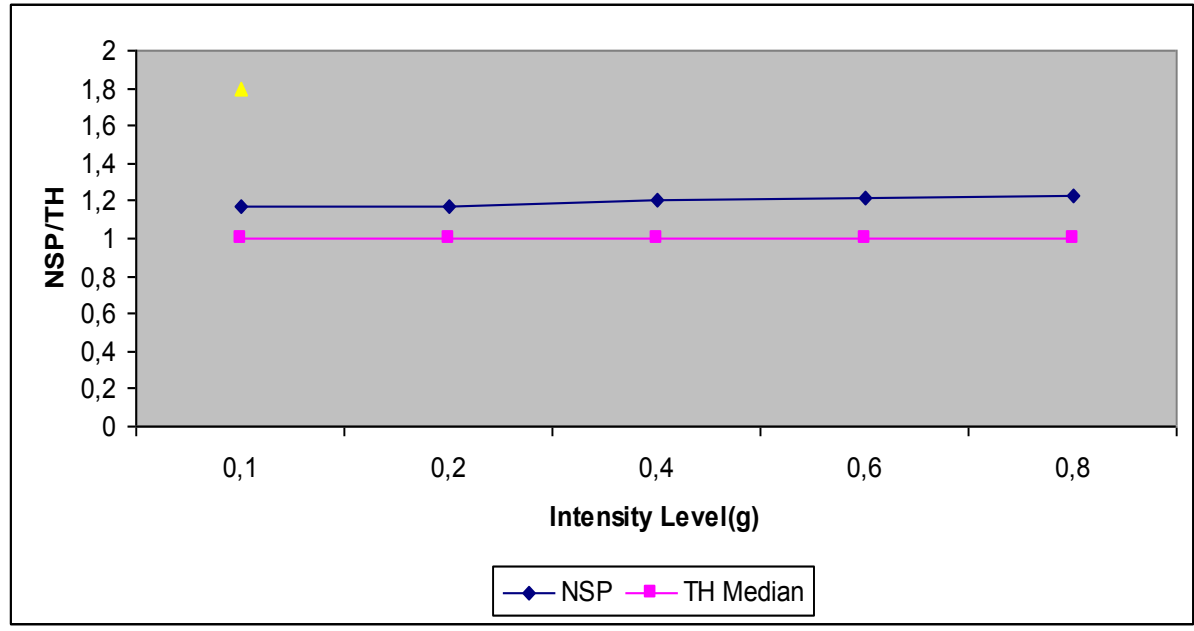

a) X Direction 


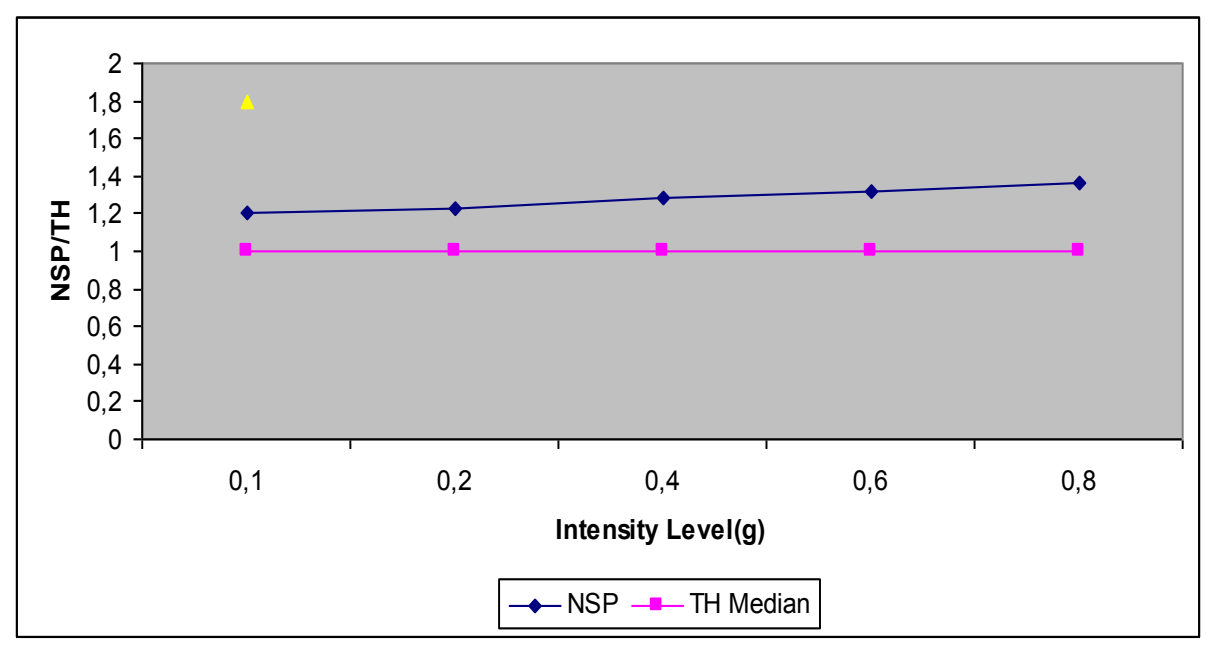

b) Y Direction

Figure 5. Top displacement ratios for column S30

Comparison of the difference between NSP and TH analysis in terms of interstory drifts, the results show that NSP values generally follow TH values. S30 column interstory drifts for $0.4 \mathrm{~g} \mathrm{X}$ direction and $0.6 \mathrm{~g} \mathrm{Y}$ direction intensity levels are shown in Figure 6.

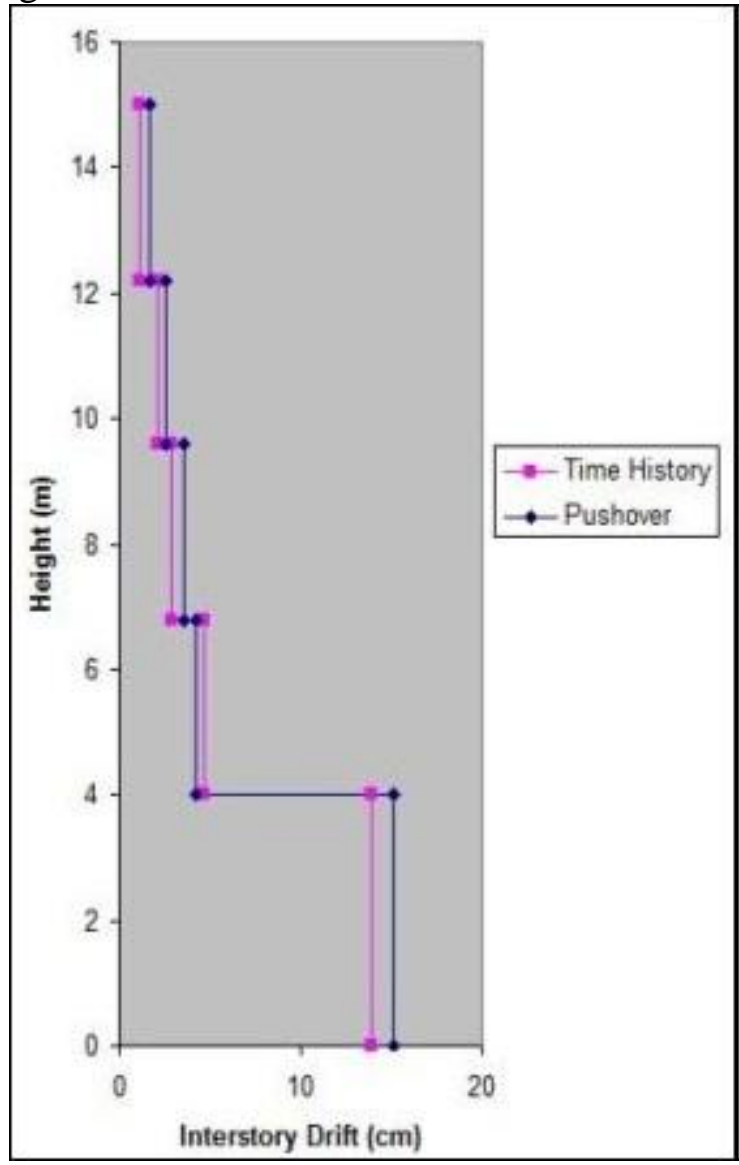

(a) $\mathrm{X}$ Direction $0.4 \mathrm{~g}$

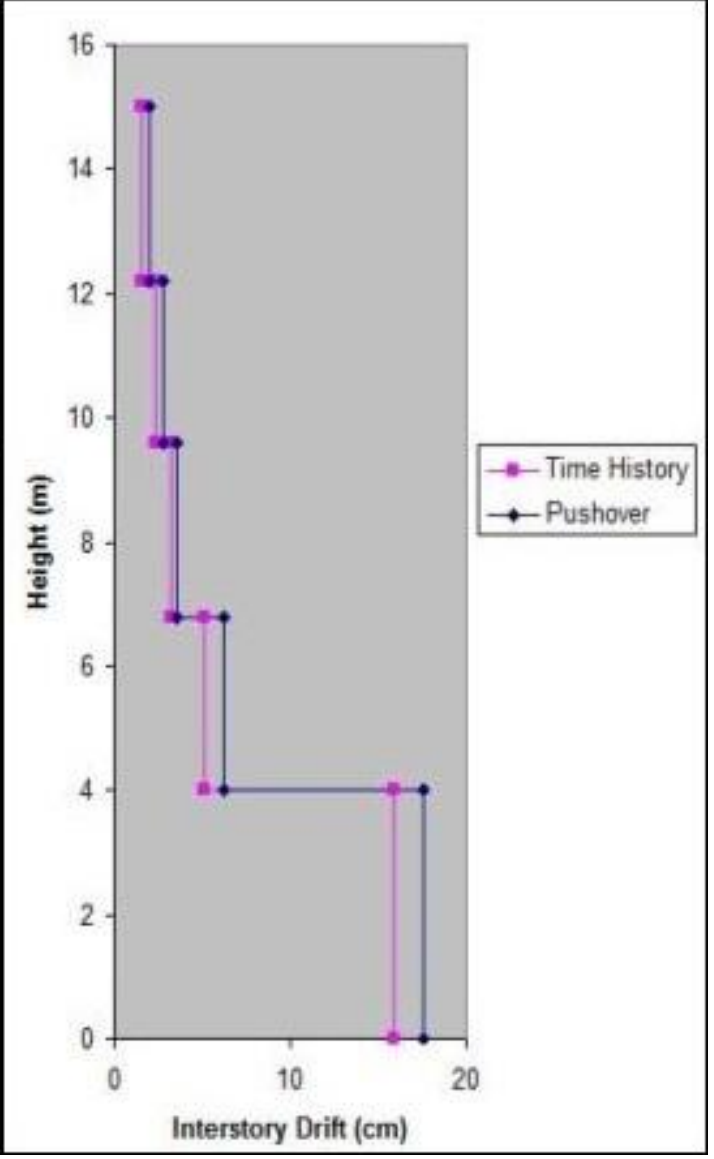

(b) Y Direction $0.6 \mathrm{~g}$

Figure 6. Interstory Drifts for Column S30 
The results in terms of lateral displacement profiles show that, once again NSP analysis results follow TH values for lower levels of intensity. S1 column lateral displacement profiles in $\mathrm{X}$ and $\mathrm{Y}$ directions for $0.4 \mathrm{~g}$ intensity levels are presented in Figure 7. S1 column lateral displacement in $\mathrm{Y}$ direction for $0.4 \mathrm{~g}$ are shown in Figure also.

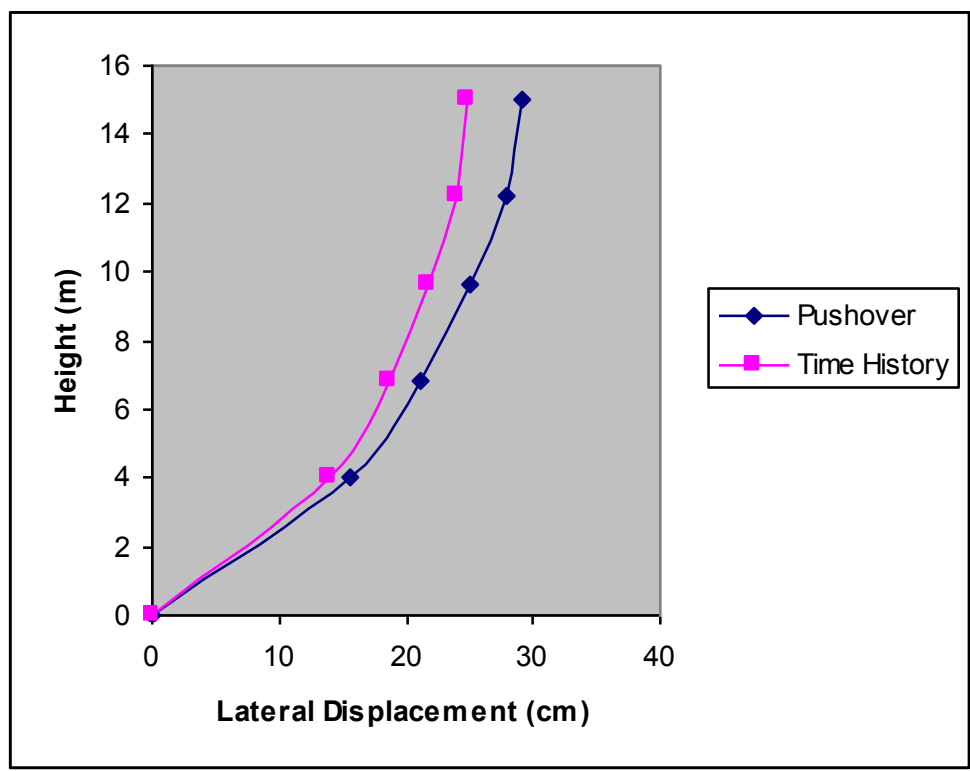

a) X Direction

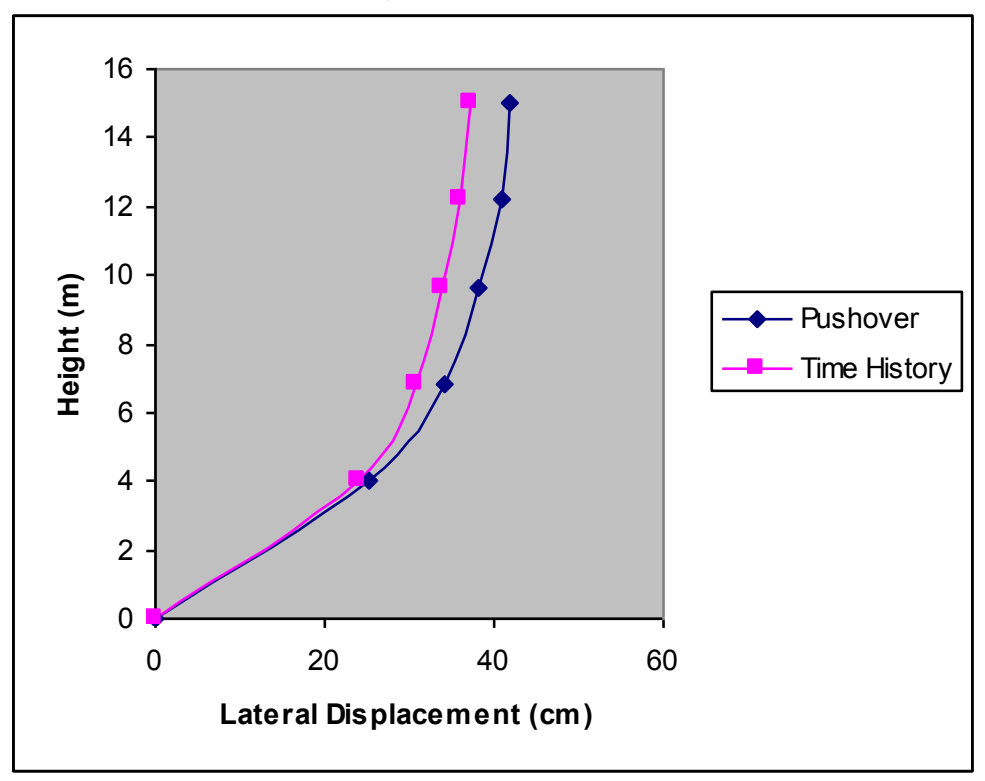

b) Y Direction

Figure 7. Column S1 lateral displacement profiles for $0.4 \mathrm{~g}$ 


\section{CONCLUSIONS}

In this study, NSP and TH analyses were applied to 5-story asymmetric building through several seismic intensities. The results were compared in terms of lateral displacement profiles, top displacement ratios and interstory drifts.

However NSP analysis has average of quick and easy application, it has some disadventages about estimating target displacements and to choose lateral loading model.

Consistency of two nonlinear method varried according to levels of intensities. NSP results consistent with TH for lower seismic intensities. As for high level of intensities, difference between the values moved away from each other.

Eventually, NSP analysis showed that acceptable results with TH analysis. Nonetheless, it is more available to use TH analysis than past years because of devoloping computer technologies and server computers with high speed processor.

\section{REFERENCES}

1. A. J. Kappos and P. Kyriakakis, A re-evaluation of scaling techniques for natural records, Soil Dynamics and Earthquake Engineering 20, 111-123, 2000.

2. V. G. Bardakis and S. E. Dritsos, Evaluating assumptions for seismic assessment of existing buildings, Soil Dynamics and Earthquake Engineering 27, 223-233, 2007.

3. D. Lee, W. Choi, C. Myung and Kim, D., Evaluation of seismic performance of multistory building structures based on the equivalent responses, Engineering Structures 28, 837-856, 2006.

4. M. Inel, H. B. Ozmen and H. Bilgin, Re-evaluation of building damage during recent earthquakes in Turkey, Engineering Structures 30, 412-427, 2008.

5. M. Saiidi and M. A. Sozen, Simple nonlinear seismic analysis of R/C structures. Journal of the Structural Division, ASCE 107, 937-51, 1981.

6. ATC-40, Seismic evaluation and retrofit of concrete buildings vols. 1-2. California. Applied Technology Council, 1996.

7. Z. Dervişoğlu, Comparison Of Performance Evaluation Methods Of Reinforced Concrete Buildings Under Earthquake Effects Within Non Linear Theory Framework, Master Thesis, Department of Civil Engineering, Balıkesir University, Balıkesir, 2007.

8. FEMA-356, Prestandard and commentary for seismic rehabilitation of buildings, Federal Emergency Management Agency, Washington, 2000.

9. FEMA-440, Improvement of Nonlinear Static Seismic Analysis Procedures, Washington, 2004.

10. TSC-2007, Specifications for buildings to be built in seismic areas. Turkish Seismic Code 2007. Ministry of Public Works and Settlement, Ankara, (Turkey).

11. Bhatt, C., Bento, R., "Comparison of Nonlinear Static Methods for the Seismic Assessment of Plan Irregular Frame Buildings with Non Sesismic Details", Journal of Earthquake Engineering 16:15-39, 2012. 